\title{
Sustainability and feasibility assessments of nanobubble aeration technology in economic- socio environment of Penaeus vannamei shrimp farming
}

\author{
Lily Susanti ${ }^{1}$, Suyud Warno Utomo ${ }^{1,2}$, and Noverita Dian Takarina ${ }^{3}$ \\ ${ }^{1}$ School of Environmental Science, Universitas Indonesia, J1. Salemba Raya 4, Jakarta 10430, \\ Indonesia \\ ${ }^{2}$ Environmental Health Department, Faculty of Public Health, Universitas Indonesia, Depok 16424, \\ Indonesia \\ ${ }^{3}$ Department of Biology, Faculty of Mathematics and Natural Sciences, Universitas Indonesia, Depok \\ 16424, Indonesia
}

\begin{abstract}
Penaeus vannamei shrimp farming in Indonesia is faced with several challenges in the environmental, economic, and social aspects. Therefore, this study aims to assess the benefits of novel nanobubble aeration systems for the ecosystem, businesses, and communities. This is an experimental study conducted by comparing $P$. vannamei post larva 10 reared at a density of 2000 inds./L in a pond treated with nanobubble and without treatments (control). Furthermore, the Net Present Value (NPV) and payback period were calculated to assess the economic feasibility of nanobubble, while community interviews were used for the social sectors. Based on the results, environmental wastes of shrimp farming in form of total ammonia nitrogen (TAN) were reduced by $9 \%$ from $2.58 \mathrm{mg} / 1$ ( $95 \% \mathrm{CI}$ : $0,91,4,25)$ in control compared to $2.35 \mathrm{mg} / 1$ (95\%CI: $0,86,3,84)$ in treatment. Furthermore, the revenues from post larva sales for five years and nanobubble investment costs showed that the estimated NPV was IDR $64,824,374$ with a payback period of 1.7 years. The interviews on traditional shrimp farming showed that $61.1 \%$ to $72.2 \%$ of community members agreed on the use of nanobubble aeration to support livelihoods. Therefore, the use of nanobubbles is feasible to support sustainable $P$. vannamei farming.
\end{abstract}

\section{Introduction}

Penaeus vannamei shrimp farming is faced with several challenges in the environmental, economic, and social aspects. The environmental impacts include development and operational, moreover, the developmental involves the conversion of coastal land to shrimp ponds which modifies the coastal habitats due to infrastructural development. Meanwhile, the operational impact is the release of nutrients or feed that is not consumed by the shrimps and becomes waste [1]. The environmental problems against the sustainability of shrimp farming are mainly due to waste from high inorganic nitrogen content, namely, ammonium 
$\left(\mathrm{NH}_{4}^{+}\right)$and nitrite $\left(\mathrm{NO}_{2}{ }^{-}\right)$, which are toxic to shrimp species and cause eutrophication in waters [2].

Economically, $P$. vannamei shrimp farming is expensive, capital intensive, and demands a considerable investment with an extended payback period. Moreover, economic considerations in selecting an appropriate $P$. vannamei shrimp farming production system include the potential for economic returns and efficiency, as well as access to capital [3]. For most shrimp farming businesses, economic efficiency is measured based on expenditure on a farming activity, namely, costs of inputs, labor, management, land cost, and capital [4]. Furthermore, shrimp farming requires efficient technology, which leads to short-term economic returns. Hence, shrimp farming technology yields a high net present value (NPV) within a short period.

In the social aspects, the success of shrimp farming and its related technology depends on farmers' acceptance. Within the Asia shrimp farming community, the adoption of technologies, standards, and practices by small and medium-scale farmers has recently become popular as one of the solutions to increase income [5]. Meanwhile, the acceptance of technology application is influenced by the profit from new aquaculture practices and technologies.

Recently, nanobubble technology [6] has been introduced in P. vannamei shrimp farming in Indonesia. However, studies on the impact of this new technology on the environmental, economic, and social aspects are limited. Therefore, this study aims to assess the benefits of novel nanobubble technology for the ecosystem, business, and community.

\section{Methodology}

\subsection{Environmental Aspect}

The environmental aspect was measured experimentally using comparisons between $P$. vannamei post larva 10 (PL10) reared at a density of 2000 inds./1 in pond treated with nanobubble and pond without treatments (control). The nanobubble treatments were divided based on oxygen concentration into $16 \mathrm{mg} / \mathrm{l}$ and $22 \mathrm{mg} / \mathrm{l}$, while the environmental variable was observed as total ammonia nitrogen (TAN). Furthermore, the TAN level was measured using Merck ammonium test kit 114657.0001 and denoted as $\mathrm{mg} / \mathrm{L}$. These measurements were conducted at 8 and 24 hours.

\subsection{Economic Aspect}

The variables measured as indicators for the economic aspect include net present value (NPV) and payback period. NPV is described as the difference between the value of net benefits obtainable in the future and the present value of benefits and costs. Furthermore, it measures the increase in present net wealth, which is equivalent to the implementation of the project. Mathematically, the NPV formula is as follows:

$$
N P V=\sum_{t=1}^{n} \frac{B t-C t}{1-i^{t}}
$$

Where NPV $=$ net present value, $\mathrm{Bt}=$ benefits in the $\mathrm{t}$-year, $\mathrm{Ct}=$ costs in $\mathrm{t}$-year, $\mathrm{i}=$ interest rates $(14 \%$ per year $), t=$ project year.

The simulation of NPV was conducted using the cost of nanobubble technology investment of IDR 55,000,000 and post larva sale for 5 years. 
The payback period (PP) for a capital budgeting project is described as the length of time for the initial investment to be recouped. Moreover, the initial investment is recouped from the net operational proceeds of the project. Mathematically, the payback period is calculated using the formula:

$$
P P=\frac{\text { investment cost }}{\text { benefit }} \times 1 \text { year }
$$

\subsection{Social Aspect}

The social aspects of shrimp farming were assessed through interviews with 36 respondents. These respondents were shrimp farmers, and the majority were male. Furthermore, the education levels ranged from junior high school to bachelor's degree, while people with higher education were working at managerial levels. The interview was based on individual opinions on the use of nanobubble technology in $P$. vannamei shrimp farming. The results were measured using a Likert scale ranging from very disagree to very agree. The effects of gender, age, and educational background on different opinions on nanobubble were analyzed using the chi-square $\mathrm{x}^{2}$ test with a significance level of $\mathrm{P}<0.05$.

\section{Results and Discussion}

\subsection{Environmental Aspects}

After 24 hours, the TAN for control and treatment groups were observed and increased by approximately four folds. Despite this increase, TAN measured from 16 and 22 treatment groups had lower values compared to the control (Figure 1). The average TAN for the control was $2.58 \mathrm{mg} / 1$ (95\%CI: 0.91, 4.25) while the treatment group was $2.35 \mathrm{mg} / 1$ (95\% CI: 0.86 , 3.84). Therefore, the use of nanobubble in PL10 hatchery reduces TAN by $9 \%$.

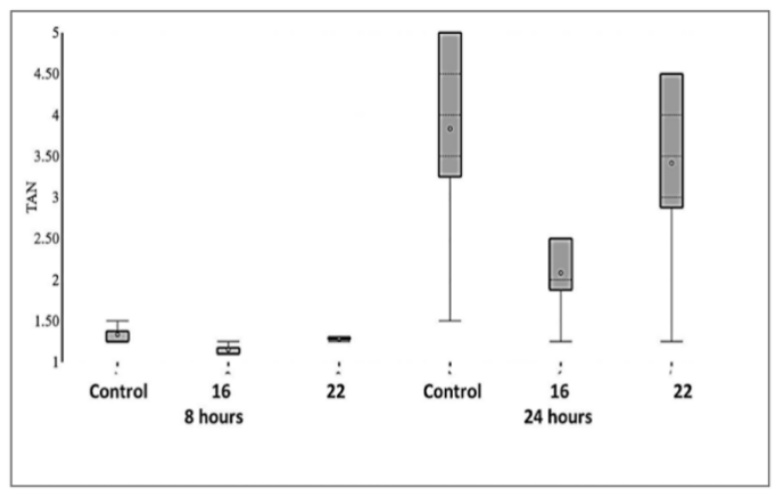

Fig. 1. Total Ammonia Nitrogen (TAN) mean levels for control, treatments (nanobubble levels: 16 $\mathrm{mg} / \mathrm{l}$ and $22 \mathrm{mg} / \mathrm{l})$ at 8 and 24 hours under PL10 density of 2000 individuals.

The increase in TAN is an important water quality for PL10 hatchery. Djunaedi et al. [7] stated that the increasing trends for ammonia and nitrite were 0.04 to $0.12 \mathrm{mg} / \mathrm{l}$ and 0.1 to $0.3 \mathrm{mg} / \mathrm{l}$ respectively. Furthermore, Sahrijanna and Sahabuddin [8] stated that the ammonia was $0.53 \mathrm{mg} / \mathrm{l}$ and nitrite was $2.32 \mathrm{mg} / \mathrm{l}$. Meanwhile, TAN is associated with PL10 hatchery from high rates of prawn excretion as well as feed loading while its high levels inversely 
affect hatchery productivity [9]. These results show that the use of nanobubble reduces TAN and conversely affect productivity.

\subsection{Economical Aspects}

The parameters of the economical aspect calculated include net present value (NPV) and payback period (PP). Based on the revenues from post larva sales for five years and the investment costs of nanobubble, the estimated NPV was IDR 64,824,374 with a payback period of 1.7 years. The nanobubble technology is feasible in shrimp farming when the NPV value is greater than zero. This zero value shows that the business returns are equivalent to the money invested. Meanwhile, the NPV of the nanobubble is projected to reach IDR $64,824,374$ in five years.

Meanwhile, the payback period is the time required to return the initial investment in form of cash flow based on total revenue minus all costs. The minimum time to recover the costs of investment in nanobubble shrimp farming is expected to be 1.7 years.

NPV is an indicator of the investment value in shrimp farming that benefits smallholder farmers. The NPV equals IDR 64,824,374, which is positive enough, and indicates that the estimated earnings from shrimp farming investment exceed the anticipated costs. Meanwhile, NPV has been used widely to assess the feasibility of shrimp aquaculture. The NPV obtained in this study is comparable to the result obtained in other areas. A previous study by Witoko et al. [10] showed that shrimp farming yields an NPV of IDR 43,315,360 with a payback period of six months.

Therefore, this study showed that the use of nanobubble technology provides positive effects on the economical aspect of shrimp farming. This result is similar to previous studies [11] where the novel technology used had a positive impact on the economic aspect. Furthermore, Oparaku and Nnaji [12] showed that the use of solar as a source of the power circulation system in fish culture was more profitable than the generator, despite its high initial capital. The solar system has a shorter payback period which is 2.69 years and faster than the conventional system that requires a payback period of 4.53 years.

\subsection{Social aspects}

The social aspects of nanobubble are shown in Figures 2, 3, and 4 which illustrate farmers' opinions on nanobubble. The majority of the respondents' educational background was high school. Based on the statistical test, the differences in gender, age, and educational background did not affect the respondents' opinions (Table 1). This shows that all respondents have similar levels of opinion on nanobubble technology.

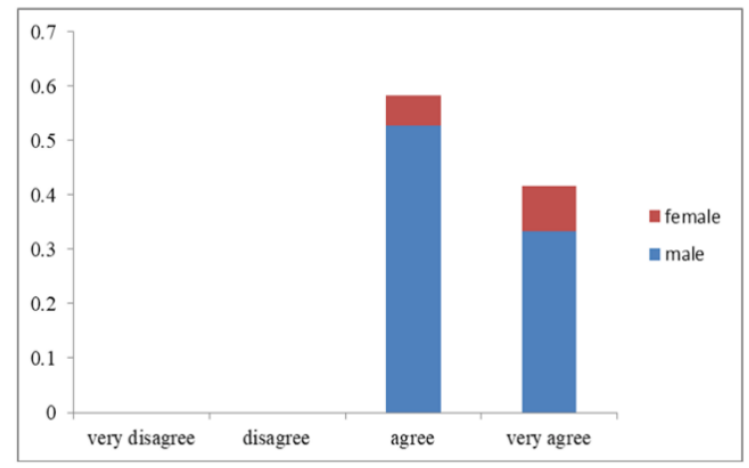

Fig. 2. Respondents' opinions on nanobubble technology based on gender. 


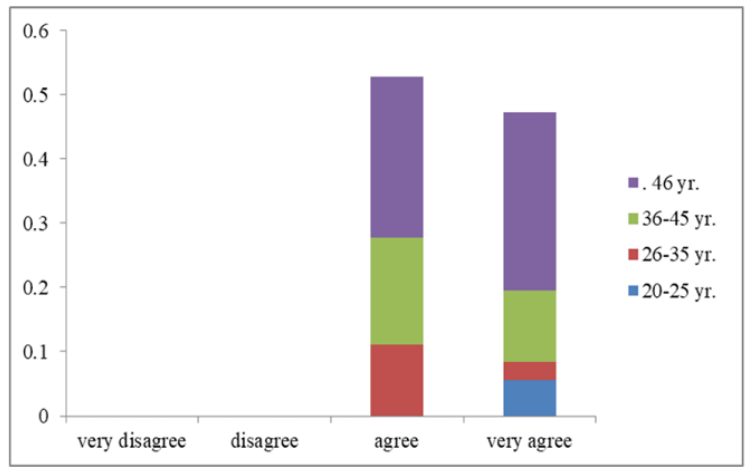

Fig. 3. Respondents' opinions on nanobubble technology based on age.

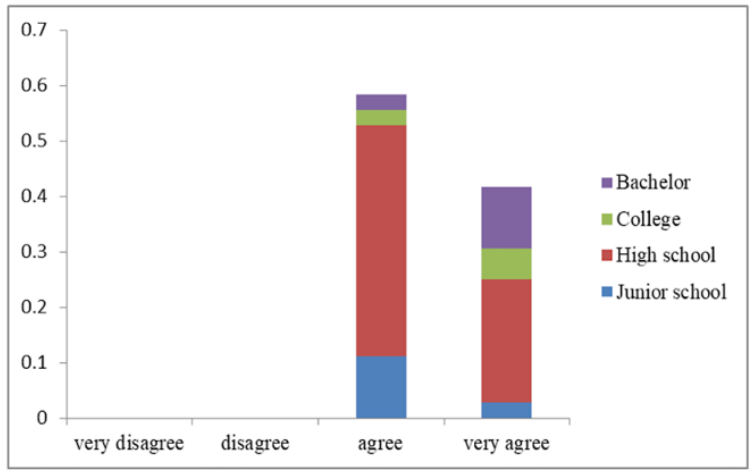

Fig. 4. Respondents' opinions on nanobubble technology based on education background.

Table 1. Chi-square $x^{2}$ test of effects of gender, age, and education background on respondents' opinions towards nanobubble

\begin{tabular}{|l|l|l|}
\hline Effects & $\mathbf{x}^{\mathbf{2}}$ & $\mathbf{P}$ \\
\hline Gender & 0.8029 & 0.370 \\
\hline Age & 2.358 & 0.501 \\
\hline Education & 5.247 & 0.263 \\
\hline
\end{tabular}

All the respondents agreed on the benefit of nanobubble technology in increasing revenues. This result is in agreement with previous studies which stated that aquaculture technology contributes to the livelihoods of the people through the improved food supply, employment, and income generation. Aquaculture technology also provides viable socio-economic alternatives to capture fisheries [13]. Moreover, it is implemented to increase the availability of edible fish, conserve the natural stock to protect biodiversity. This technology also serves as one of the best alternatives for the over-exploited natural aquatic resources. Therefore, aquaculture technology, especially nanobubbles, helps to reduce environmental pressure and maintain the ecological balance of the natural ecosystems $[14,15]$. Meanwhile, there is no correlation among the gender, age, and educational background of the respondents' opinions. This shows that the information on nanobubbles is well recognized, widely disseminated, and easily understood by the farmers. Also, access to detail information on the introduced aquaculture technology is an important factor that affects its acceptance among shrimp farmers [16]. 


\section{Conclusions}

This study provided empirical evidence on the impact of nanobubble technology on the environmental, economical, and social aspects. The result shows that nanobubble is feasible to be implemented because it provides great benefits by reducing TAN, NPV yield, and gaining the trust of shrimp farmers.

\section{References}

1. F. Páez-Osuna, Environmental Management 28, 131-140 (2001)

2. C. T. Eng, J. N. Paw, F. Y. Guarin, Marine Pollution Bulletin 20, 7, 335-343 (1989)

3. W. B. Green, Z. EI. Nagdy, H. Hebicha, I. Shake, D. A. R. Kenawy, A. R. EI. Gamal, Research report 95-91. Pond dynamics/ aquaculture collaborative research support program (1995)

4. R. E. Brummett, FAO Fisheries Proceedings. No. 10. Rome, FAO. Pp. 221-228 (2007)

5. A. Diedrich, J. Blythe, E. Petersen, E. Euriga, A. Fatchiya, T. Shimada, C. Jones, Sustainability (2019)

6. D. P. Galang, A. K. Ashari, L. Sulmatiwi, G. Mahasri, Prayogo, L. A. Sari, IOP Conf. Series: Earth and Environmental Science 236 (2019)

7. A. Djunaedi, H. Susilo, Sunaryo Jurnal Kelautan Tropis 19, 171. (2016)

8. A. Sahrijanna, Sahabuddin. Prosiding Forum Inovasi Teknologi (2014)

9. G. Valencia-Castañeda, M. Frías-Espericueta, C. J. Vanegas, Pérez-Ramírez, C. Chavez-Sanchez, F. Páez-Osuna, Bulletin of Environmental Contamination and Toxicology 101, 1-6 (2018)

10. P. Witoko, N. Purbosari, N. M. Noor, Manajemen IKM, September:175-179 (2018)

11. M. S. de Almeida, J. R. Carrijo-Mauad, R.M.T Gimenes, Aquacult Int (2021)

12. N. F. Oparaku, C. E. Nnaji. International Journal of Physical Sciences 8, 43, 20002010 (2013)

13. FO Agbebi, International Journal of Science and Nature 2, 456-460 (2011)

14. D. Dereje, L.P. Devi, V Sreenivasa, G. Abebe, International Journal of Aquaculture (2015)

15. A. Kassahun Natural Resources and Applied Life Sciences (2012)

16. A. A. Ijah, O. N Oladele, B. F. Ishola, J. T. Ayodele, U. F. Government Area of Kaduna State, Nigeria. Asian Journal of Fisheries and Aquatic Research 8, 1, 14-29 (2020) 